\title{
Hole doping in high temperature superconductors using the XANES technique
}

\author{
N M Hamdan' and Z Hussain ${ }^{2}$ \\ I Physics Department, American University of Sharjah, Sharjah 26666, United Arab Emirates \\ ${ }^{2}$ Advanced Light Source, LBNL, Berkeley, CA 94720, USA \\ E-mail: nhandan@aus.edu
}

Received 1 September 2008, in final form 24 November 2008

Published 28 January 2009

Online at stacks.iop.org/SUST/22/034007

\begin{abstract}
Superconducting and physical properties of F-doped $\mathrm{HgPb}-1223$ and Ce-doped Tl-1223 systems were considerably improved through adjusting the hole content of the two systems. In this study, we have used the x-ray absorption near-edge structure (XANES) technique to investigate the electronic structure of the two systems by probing the unoccupied electronic states. For the F-doped $\mathrm{Hg}-1223$ system, the $\mathrm{O}$ K-edge, $\mathrm{Ca} \mathrm{L}_{2,3}$ and $\mathrm{Cu} \mathrm{L}_{2,3}$-edge structures were thoroughly investigated. The pre-edge features of $\mathrm{O} \mathrm{K}$-edge spectra, as a function of doping, reveal important information about the projected local density of unoccupied states on the $\mathrm{O}$ sites in the region close to the absorption edge, which is a measure of $\mathrm{O} 2 \mathrm{p}$ hole concentration in the valence band. In the originally under-doped $\mathrm{Hg}-1223$, the results indicate that the number of $\mathrm{O} 2 \mathrm{p}$ holes in the $\mathrm{CuO}_{2}$ planes increases as fluorine was introduced up to an optimal value, after which it decreases. Furthermore, the $\mathrm{Cu} \mathrm{L}_{2,3}$ absorption edge provides useful information about the valence state of $\mathrm{Cu}$ which is also related to the hole density in the $\mathrm{CuO}_{2}$ planes and confirms the same previous conclusion. The $\mathrm{Ca} \mathrm{L}_{2,3}$-edge shows the presence crystal field splitting in $\mathrm{HgPb} 1223 / \mathrm{F}_{x}$ which is similar to $\mathrm{CaF}_{2}$ and $\mathrm{CaO}$ in addition to the spin-orbit splitting of the Ca $2 p$ core level electrons. These results ensure that fluorine goes into the structure of $\mathrm{HgPb}-1223 / \mathrm{F}_{x}$ and it occupies the vacant interstitial oxygen site in the $\mathrm{Hg}-\mathrm{O}$ plane, as was expected. In Ce-substituted Tl-1223, similar measurements were performed for samples with different $\mathrm{Ce}$ content. The pre-edge feature of the $\mathrm{O} \mathrm{K}$-edge spectra shows clearly the drastic decrease of the hole content in $\mathrm{CuO}_{2}$ planes of this originally over-doped system with increasing $\mathrm{Ce}$ content. This result is also confirmed from the chemical state of $\mathrm{Ce}$ in the structure as obtained from the $\mathrm{Ce} \mathrm{M}_{4,5}$-edge spectra.
\end{abstract}

(Some figures in this article are in colour only in the electronic version)

\section{Introduction}

Hole concentration in $\mathrm{CuO}_{2}$ planes of high temperature superconductors plays an important role in determining their superconducting and normal state properties $[1,2]$. The transition temperature $\left(T_{\mathrm{c}}\right)$ of most high temperature superconductors and the critical current densities are sensitive to the number of holes in the $\mathrm{CuO}_{2}$ planes. Controlling the hole content in the $\mathrm{CuO}_{2}$ planes can be achieved by different methods: anion substitution (fluorine for oxygen, for example), cation substitution and oxygen non-stoichiometry that can be achieved either by varying the annealing conditions or by irradiation effects. In this work, we will consider anion and cation substitution in $\mathrm{Hg}$-based and $\mathrm{Tl}$-based compounds, respectively. Tl-based and $\mathrm{Hg}$-based superconductors are particularly sensitive to the number of holes in the $\mathrm{CuO}_{2}$ planes, especially for the technologically important Tl- 1223 and $\mathrm{HgPb}-1223$ phases. Usually, as-prepared samples of $\mathrm{Tl}-1223$ are over-doped, while samples of $\mathrm{HgPb}-1223$ are under-doped. Optimizing the hole concentration in these systems had been the concern of several groups [3-6]. Cation substitutions for various elements in these compounds were 
performed in attempts to control the hole concentration in the $\mathrm{CuO}_{2}$ planes and to increase $T_{c}$. Although this method has been extensively used by many groups for all known high temperature superconducting systems, it sometime poses serious problems. These problems are related to the fact that the substituted cation can enter the structure at various and multiple atomic sites and therefore can affect the stoichiometry and cause the formation of unwanted impurity phases. We have performed anion substitution for both the over-doped Tl-1223 and the under-doped $\mathrm{Hg}-1223$ systems. Oxygen was partially replaced with the more electronegative fluorine in the Tl-1223 system. We have achieved significant enhancements of both the transition temperature and the critical current density in this system $[1,7,8]$. Furthermore, considerable improvements of the phase formation and normal state properties have been achieved. These enhancements were attributed to optimizing the hole concentration in the $\mathrm{CuO}_{2}$ planes. We have also studied the effect of $\mathrm{Ce}$ substitution for $\mathrm{Sr}$ in samples that consist of the two phases Tl-1223 and Tl-1212 [9, 10]. We have also observed an enhancement of the superconducting properties for small values of Ce concentration $x$, followed by a deterioration in the superconducting properties for higher values of $x$.

Mercury-based high temperature superconductors are unique among other cuprate superconductors, because they have the highest $T_{\mathrm{c}}$ so far, and $T_{\mathrm{c}}$ strongly depends on the applied hydrostatic pressure. $\mathrm{HgBa}_{2} \mathrm{Ca}_{2} \mathrm{Cu}_{3} \mathrm{O}_{8+\delta}(\mathrm{Hg}-$ 1223) have $T_{c}$ above $130 \mathrm{~K}$ under ambient atmosphere and it increases to above $160 \mathrm{~K}$ under high pressure [11]. This property has led to considerable research activities on this system. Structural investigations under high pressure have revealed a drastic shortening of the apical $\mathrm{Cu}-\mathrm{O}$ distance, which is possibly linked to the increase in $T_{\mathrm{c}}$ [12]. Neutron diffraction results have also shown that excess oxygen has the same effect on the crystal structure of this compound as that when subjected to high pressure [13]. On the other hand, band structure calculations using the local density approximation (LDA) have predicted an increase in $T_{\mathrm{c}}$ with the increase in the density of holes in the $\mathrm{Cu}-\mathrm{O}$ planes [14]. This is equivalent to insertion of excess oxygen into the $\mathrm{HgO}_{\delta}$ planes $[15,16]$. Novikov and Freeman have also observed similar effects on the position of the $\mathrm{Hg} 6 \mathrm{p}_{z}$ and the $\mathrm{O} 2 \mathrm{p}_{z}$ state near the Fermi level [16]. The variation of the excess oxygen $\delta$ modifies the charge carrier concentration in the $\mathrm{CuO}_{2}$ planes and hence changes $T_{\mathrm{c}}$ [17].

It is well established that the substitution of transition elements such as $\mathrm{Pb}, \mathrm{Re}$ and $\mathrm{Bi}$ for $\mathrm{Hg}$ simplifies the synthesis, and improves and stabilizes the phase formation of $\mathrm{Hg}$-based superconductors [18-20]. Furthermore, partial substitution of mercury by a high valence transition metal introduces extra oxygen atoms in the $\mathrm{HgO}_{\delta}$ plane [17], and hence improves its superconducting properties. It was also established that partial substitution of $\mathrm{Pb}, \mathrm{Re}$ or $\mathrm{Bi}$ for $\mathrm{Hg}$ does not drastically increase the transition temperature $T_{\mathrm{c}}$ as expected from high-pressure measurements. This made us believe that there is still a possibility of further improving the superconducting properties, which could be attempted by anion substitution. Therefore, and because we have achieved considerable improvements in the superconducting properties and phase formation of Tl-1223 through fluorine substitution [1,21-24], we have attempted to optimize the properties of $\mathrm{Hg}-1223$ by introducing fluorine into the structure for both the $\mathrm{Pb}$-doped ( $\mathrm{HgPb}-1223$ and the Re-doped HgRe1223). In this work we will restrict our discussions to the $\mathrm{HgPb}-1223$ system. Although $\mathrm{Tl}-1223$ and $\mathrm{HgPb}-1223$ phases have similar structures, there is a major difference that affects the hole distribution in the $\mathrm{CuO}_{2}$ planes and hence the electronic structure of both compounds [21-25]. This difference is in the $\mathrm{O}$ site of $\mathrm{Tl}-\mathrm{O}$ and the corresponding $\mathrm{Hg}-\mathrm{O}$ planes where it is fully occupied and partially filled in Tl-1223 and $\mathrm{Hg}-1223$, respectively. Therefore, fluorine was introduced in the $\mathrm{Cu}-\mathrm{O}$ planes in the case of $\mathrm{Tl}-1223$ but it was expected to fill the partially filled site in the $\mathrm{Hg}-\mathrm{O}$ planes in $\mathrm{Hg}-223$. This led to increasing the hole concentration of the originally under-doped $\mathrm{Hg}-1223$, and to decreasing it in the over-doped T1-1223 [21-26].

We have also achieved considerable improvements in the critical current density of both $\mathrm{Re}$-and $\mathrm{Pb}$-doped $\mathrm{Hg}$ 1223, and a $2 \mathrm{~K}$ increase in $T_{\mathfrak{c}}$, by incorporating fluorine into the structure in the case of fluorinated Pd-doped $\mathrm{Hg}$ 1223 [26, 28]. Putilin et al and Lockshin et al [28, 29] have observed a $4 \mathrm{~K}$ enhancement in the transition temperature of fluorinated Hg-1223. Wang and Hermann have also observed a considerable increase in the hysteresis magnetization of fluorinated $\mathrm{Hg}-1223$ [30]. Our structural, electrical and magnetic measurements in both fluorinated Tl-based and $\mathrm{Hg}$-based systems have demonstrated that the observed improvement in the properties of these two systems with fluorine addition are due to changes of the number of charge carriers in the $\mathrm{CuO}_{2}$ planes [21-24, 26, 27].

Because of the importance of understanding the role of the density of holes in $\mathrm{CuO}_{2}$ planes, and its relation to filling the partially vacant oxygen site in the $\mathrm{Hg}-\mathrm{O}_{\delta}$ plane, and the dependence of $T_{\mathrm{c}}$ on the value of $\delta$ [32], detailed measurements of electronic structural features in the $\mathrm{Hg}-1223$ system are necessary. The hole state that is directly related to the $\mathrm{Hg} 6 \mathrm{p}_{z}$ hybridization with $\mathrm{O}(2) 2 \mathrm{p}_{z}$ states [32], and the valence state of $\mathrm{Cu}$, are among the electronic properties that could be investigated by near-edge $x$-ray absorption fine structure measurements. Therefore, we have investigated the effect of fluorine addition on $\mathrm{Pb}$-doped $\mathrm{Hg}-1223(\mathrm{HgPb}-$ $1223 / \mathrm{F}_{x}$ ) on the XANES spectra (O K-edge, $\mathrm{Cu} \mathrm{L} \mathrm{L}_{2,3}$-edges, $\mathrm{Ca} \mathbf{L}_{2,3}$ ) for samples with different fluorine content $x$. We will also present in this work XANES spectra at the $O$ K-edge, $\mathrm{Cu} \mathrm{L} \mathrm{L}_{2,3}$-edges and $\mathrm{Ce} \mathrm{M}_{4,5}$-edges for $\left(\mathrm{Tl}_{0.5} \mathrm{~Pb}_{0.5}\right)$ $\mathrm{Sr}_{2-x} \mathrm{Ce}_{x} \mathrm{Ca}_{2} \mathrm{Cu}_{3} \mathrm{O}_{10}$ samples. The purpose of this part of the work is to demonstrate that the Ce substitution in Tl-1223 reduces the hole concentration in the $\mathrm{CuO}_{2}$ planes and hence affects the superconducting properties of Tl-1223. This is done by measuring the valence state of $\mathrm{Ce}$ in the structure and the projected local density of unoccupied states on the $O$ sites in the region very close to the absorption edge which is a measure of $O 2 p$ hole concentration in the valence band. 


\section{Experimental details}

The solid state reaction technique in sealed quartz tubes was used to prepare the single-phase $\mathrm{Hg}-1223$ samples with different fluorine contents used in this study. Samples with composition $\mathrm{Hg}_{0.8} \mathrm{~Pb}_{0.2} \mathrm{Ba}_{2} \mathrm{Ca}_{2} \mathrm{Cu}_{3} \mathrm{O}_{8+\delta} / \mathrm{F}_{x} \quad\left(\mathrm{HgPb}-1223 / \mathrm{F}_{x}\right)$ were prepared with nominal fluorine content $(x=0.000$, $0.050,0.120,0.185,0.285$ and 0.500 ). The transition temperatures $\left(T_{\mathrm{c}}\right)$ for samples with different fluorine content were determined from magnetization versus temperature measurements using a SQUID magnetometer. $T_{\mathrm{c}}$ for some of the samples was double-checked by measuring the resistivity versus temperature utilizing the four-point probe technique. The critical current density determined from magnetic hysteresis and Bean's critical state model has also been determined from hysteresis loops measured also by SQUID in magnetic fields up to $5.5 \mathrm{~T}$. The phase formation and the microstructure of the samples have also been modified through fluorine inclusion that was evident from large size, platelet-like grains. Details of the preparation and characterization of the samples were published elsewhere [26, 27].

Six samples with nominal composition of $\left(\mathrm{Tl}_{0.5} \mathrm{~Pb}_{0.5}\right)$ $\mathrm{Sr}_{2-x} \mathrm{Ce}_{x} \mathrm{Ca}_{2} \mathrm{Cu}_{3} \mathrm{O}_{10}$ were prepared by the solid state reaction technique with $x=0.0,0.1,0.2,0.3,0.4$ and 0.5 . Details of the preparation were published elsewhere $[8,9]$. The samples were characterized using resistivity, magnetization, scanning electron microscopy, EDS and $x$-ray diffraction measurements.

The $\mathrm{x}$-ray absorption measurements at the $\mathrm{O} \mathrm{K}$-edge, $\mathrm{Ca}$ $\mathrm{L}_{2,3}$-edge, $\mathrm{Ce} \mathrm{M}_{4,5}$-edges and $\mathrm{Cu} \mathrm{L}_{2,3}$-edges were carried out at beamline 9.3.2 at the Advanced Light Source, Lawrence Berkeley National Laboratory. The beamline is equipped with a spherical grating monochromator (SGM) that provides photons with energies in the range $(30-1000) \mathrm{eV}$. The experiments were performed with a resolution better than $0.1 \mathrm{eV}$ for the oxygen K-edge and $\mathrm{Ca}$ L-edge and $0.15 \mathrm{eV}$ for the $\mathrm{Cu} \mathrm{L}_{2,3}$-edges and $\mathrm{Ce} \mathrm{M}_{4,5}$. Polycrystalline samples were in situ scraped to get clean fresh surfaces. The pressure in the XANES experimental chamber was about $1 \times 10^{-10}$ Torr. The spectra were recorded by detecting the total electron yield (TEY) from the samples drain current. TEY is a surface-sensitive technique, unlike the $\mathrm{x}$-ray fluorescence yield (XFY) which is a bulk-sensitive measurement. Therefore TEY data do not require self-absorption correction [33]. The $I_{0}$ signal from a gold grid upstream from the beamline was also recorded for normalization purposes and to monitor the energy calibration from the $\mathrm{Cr}_{2} \mathrm{~L}_{2,3}$-edges' absorption signal in $I_{0}$ which originates from the $\mathrm{Cr}$ on the beamline gratings. The samples were mounted to a molybdenum holder with UHV-compatible double-sided conductive tape. Background subtraction was performed using a linear background fit for the energy region prior to each absorption edge. $600 \mathrm{l} \mathrm{mm}^{-1}$ spherical gratings were used for the measurements of the $\mathrm{O} K$ and $\mathrm{Ca} \mathrm{L}_{2,3}$-edges while a $1200 \mathrm{l} \mathrm{mm}^{-1}$ grating was used to measure both $\mathrm{Ce}_{4,5}$ and $\mathrm{Cu} \mathrm{L}_{2,3}$-edges. The monochromator was calibrated by running $x$-ray photoemission spectra (XPS) for Au samples at different photon energies.

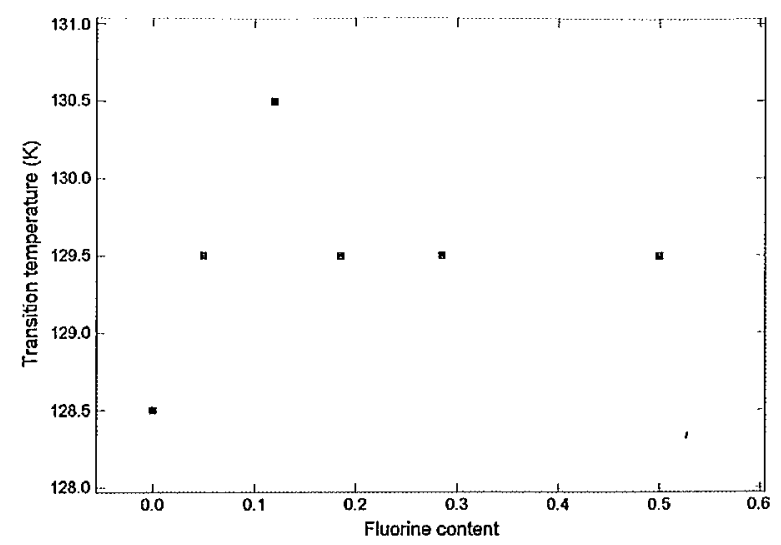

Figure 1. Variation of the transition temperature $T_{\mathrm{c}}$ of $\mathrm{Hg}-1223 / \mathrm{F}_{x}$ with nominal fluorine content $x$.

\section{Results and discussions}

3.1. Anion substitution (fluorine for oxygen) in $\mathrm{Hg}-\mathrm{Pb}-12223$ system

3.1.1. Oxygen $K$-edge. Effect of fluorine substitution on the superconducting properties of $\mathrm{Hg}_{0.8} \mathrm{~Pb}_{0.2} \mathrm{Ba}_{2} \mathrm{Ca}_{2} \mathrm{Cu}_{3} \mathrm{O}_{y} / \mathrm{F}_{x}$ $\left(\mathrm{HgPb}-1223 / \mathrm{F}_{x}\right)$ with $x=0.00,0.05,0.120,0.185,0.285$ and 0.500 was investigated. We have found an increase in $T_{\mathrm{c}}$ as $\mathrm{F}$ was introduced into the structure of the $\mathrm{Pb}$-substituted $\mathrm{Hg}$ 1223 [26]. Furthermore, the critical current density and both its magnetic field and temperature dependence were found to be greatly enhanced for both the $\mathrm{Pb}$-and $\mathrm{Re}$-doped $\mathrm{Hg}-1223$ as fluorine was introduced $[26,27]$. These improvements in the superconducting properties are believed to be due to changes in the charge carrier concentration in the $\mathrm{CuO}_{2}$ planes and improvement of the inter-and intra-grain pinning mechanism. These conclusions were made based on the variation of the superconducting, electrical, magnetic and structural properties of the system as fluorine was introduced $[26,27]$. In this study, we have directly probed the density of holes in various planes of this system by measuring the $\mathrm{O} \mathrm{K}$-edge and $\mathrm{Cu} \mathrm{L}_{2,3}$-edges as a function of fluorine. Figure 1 shows the variation of $T_{\mathrm{c}}$ of $\mathrm{Hg}-1223 / \mathrm{F}_{x}$ samples with fluorine content $x . T_{\mathrm{c}}$ increases for low fluorine content and then slightly drops, then saturates. $T_{\mathrm{c}}$ values were obtained from magnetic measurements using a SQUID magnetometer. Details of characterizations are published elsewhere $[26,27]$. The samples were single phase with a superconducting volume fraction of more than $95 \%$.

Figure 2 shows the $\mathrm{O} \mathrm{K}$-edge XANES spectra for $\mathrm{HgPb}$ $1223 / \mathrm{F}_{x}$ with different $\mathrm{F}$ content $x$. The pre-edge peak $\mathrm{A}$ at about $528.3 \mathrm{eV}$ is attributed to the transition of $\mathrm{O} 1 \mathrm{~s}$ electrons to $\mathrm{O} 2 \mathrm{p}$ holes in the $\mathrm{CuO}_{2}$ planes from $3 \mathrm{~d}^{9} \mathrm{~L} \rightarrow \mathrm{O} 1 \mathrm{~s} 3 \mathrm{~d}^{9}(\mathrm{~L}$ denotes a hole on the $\mathrm{O} 2 \mathrm{p}_{x, y}$ orbital) states corresponding to the creation of a core hole on the $\mathrm{O}$ is level and filling of $\mathrm{O} 2 \mathrm{p}_{x, y}$ states located in the $\mathrm{CuO}_{2}$ planes near the Fermi level. The assignment of this peak to the $\mathrm{O} 2 \mathrm{p}_{x y}$ symmetry rather than the out-of-plane $\mathrm{O} 2 \mathrm{p}_{z}$ symmetry is confirmed by several polarization studies [14, 34-37]. Chen et al, for example found that the intensity of this pre-edge peak in Tl2223 decreases with increasing the polarized light's incident 


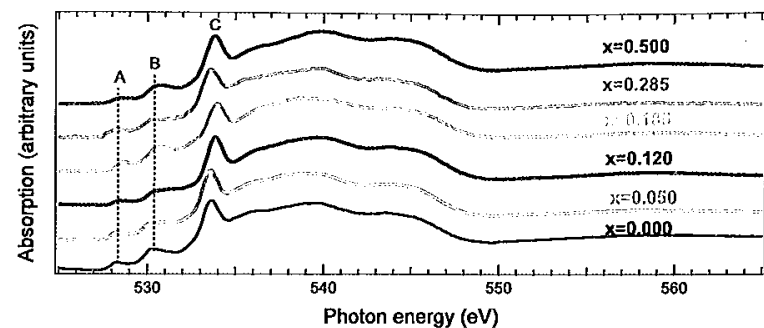

Figure 2. O K-edge of $\mathrm{HgPb}-1223 / \mathrm{F}_{x}$ as a function of fluorine content $x$.

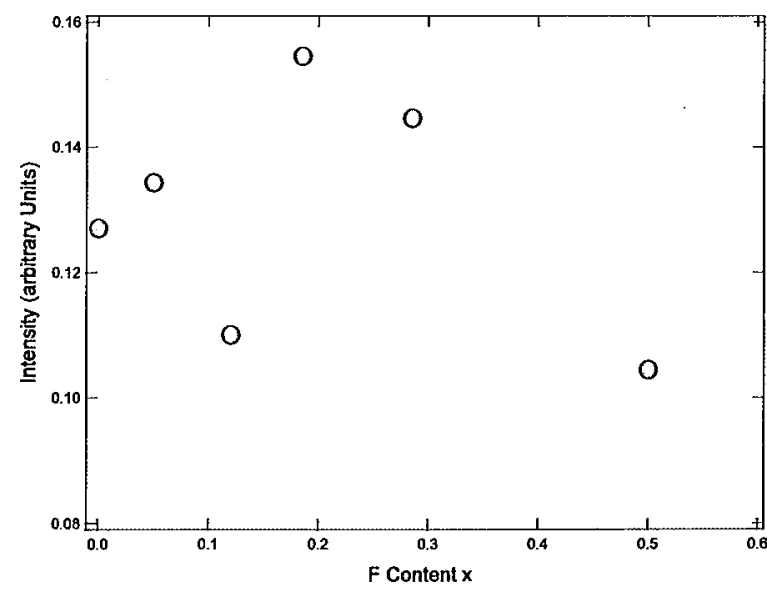

Figure 3. Variation of the intensity of the pre-edge peak in the $\mathrm{O}$ K-edge (feature $\mathrm{A}$ in figure 2) with $\mathrm{F}$ content $x$.

angle with the $c$ axis [31]. The intensity of this peak in figure 2, slightly increases with increasing fluorine content up to an optimum value of $x$, as shown in figure 3. The behavior of this peak for the sample with $x=0.120$ is inconsistent with other samples. This behavior could be attributed to the lack of homogeneity of this particular small piece of the sample that had been used for XANES measurement. The changes

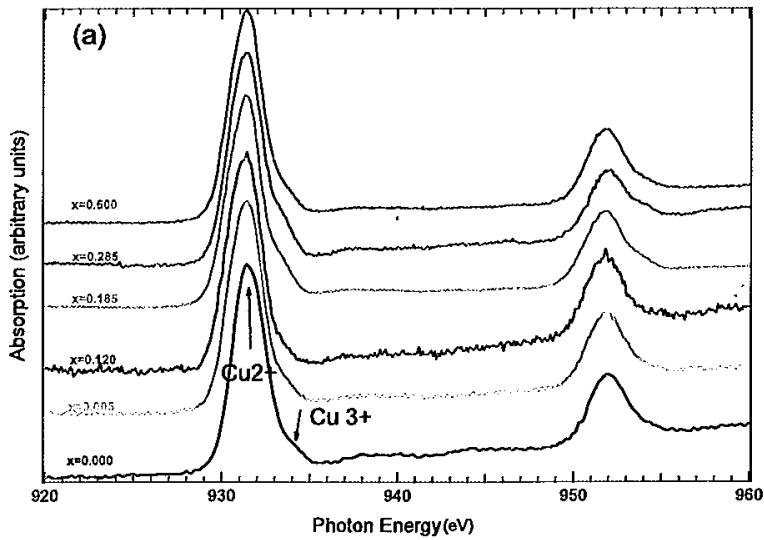

in the intensity of this peak are responsible for fine-tuning the hole content in the $\mathrm{CuO}_{2}$ planes, mostly by filling the vacant oxygen site in the $\mathrm{Hg}-\mathrm{O}$ planes with fluorine [25]. The preedge peak $\mathrm{B}$, at about $530 \mathrm{eV}$, is ascribed to the transition of $\mathrm{O} 1 \mathrm{~s}$ to $\mathrm{O} 2 \mathrm{p}$ holes in the $\mathrm{Ba}-\mathrm{O}$ planes. This peak could also be associated with the transition of the $\mathrm{Cu} 3 \mathrm{~d}$ states hybridized with the $\mathrm{O} 2 \mathrm{p}$ states to the upper Hubbard band [38, 39]. Peak $\mathrm{C}$ is ascribed to $\mathrm{O} 2 \mathrm{p}$ holes in the $\mathrm{Hg}-\mathrm{O}$ planes [17]. The spectral features above $535 \mathrm{eV}$ reveal information about the local density of unoccupied states corresponding to $\mathrm{O} 2 \mathrm{p}$ states hybridized with $\mathrm{Cu} 4$ sp and $\mathrm{Ba} / \mathrm{Ca}$ intermixing [34-39]. $\mathrm{HgPb}-$ 1223 has four nonequivalent oxygen sites: $O(1)$ and $O(1)$ within the $\mathrm{CuO}_{2}$ layers of the square planner and pyramidal arrangements, respectively, $\mathrm{O}(2)$ in the $\mathrm{Ba}-\mathrm{O}$ and $\mathrm{O}(3)$ in the $\mathrm{Hg}-\mathrm{O}$ planes $[26,31,32,36]$.

3.1.2. $\mathrm{Cu} L_{2,3}$ edges. The $\mathrm{Cu} \mathrm{L}_{2,3}$ absorption spectra of $\mathrm{HgPb}-1223 / \mathrm{F}_{x}$ as a function of fluorine content $x$ are shown in figure $4(a)$ in the energy range $(920-960) \mathrm{eV}$. The spectra consist of two main white lines at $931.3 \mathrm{eV}$ and a wider peak at about $952 \mathrm{eV}$. A high energy shoulder of the main two peaks and a wide structure at about $943 \mathrm{eV}$ are present. This wide feature is only clear in the fluorine-free sample and samples with low fluorine content and is absent in the spectrum of samples with higher fluorine content. The main white lines are ascribed to the transition from $\mathrm{Cu}\left(2 \mathrm{P}_{3 / 2,1 / 2}\right) 3 \mathrm{~d}^{9}-\mathrm{O} 2 \mathrm{p}^{6}$ ground state into the $\mathrm{Cu}\left(2 \mathrm{P}_{3 / 2,1 / 2}\right)^{-1} 3 \mathrm{~d}^{10}-\mathrm{O} 2 \mathrm{p}^{6}$ exited state, where $\left(2 \mathrm{P}_{3 / 2,1 / 2}\right)^{-1}$ denotes a $2 \mathrm{P}_{3 / 2}$, or $2 \mathrm{P}_{1 / 2}$ hole. These transitions are due to divalent copper, i.e. $\mathrm{Cu}^{+\mathrm{II}}$ state. The high energy shoulder of both the $\mathrm{L}_{2}$ and $\mathrm{L}_{3}$ edges are due to copper in the trivalent state and attributed to the transition of $\mathrm{Cu}\left(2 \mathrm{p}_{3 / 2,1 / 2}\right) 3 \mathrm{~d}^{9} \mathrm{~L}$ ground state into the $\mathrm{Cu}\left(2 \mathrm{p}_{3 / 2,1 / 2}\right)^{-1} 3 \mathrm{~d}^{10} \mathrm{~L}$ excited state, where $L$ denotes a ligand hole in the $O 2 p$ orbital [37-40].

The variation of the intensity of the $\mathrm{Cu}^{+\mathrm{HII}} / \mathrm{Cu}^{+\mathrm{II}}$ is shown in figure $4(\mathrm{~b})$. The figure shows that the intensity of the $\mathrm{Cu}^{+ \text {III }}$ peak increases as fluorine content was increased beyond $x=0.2$ as a result of $\mathrm{F}$ incorporation into the structure. This means that there will be more $\mathrm{O} 2 \mathrm{p}$ holes in the $\mathrm{Cu}-\mathrm{O}$ planes.

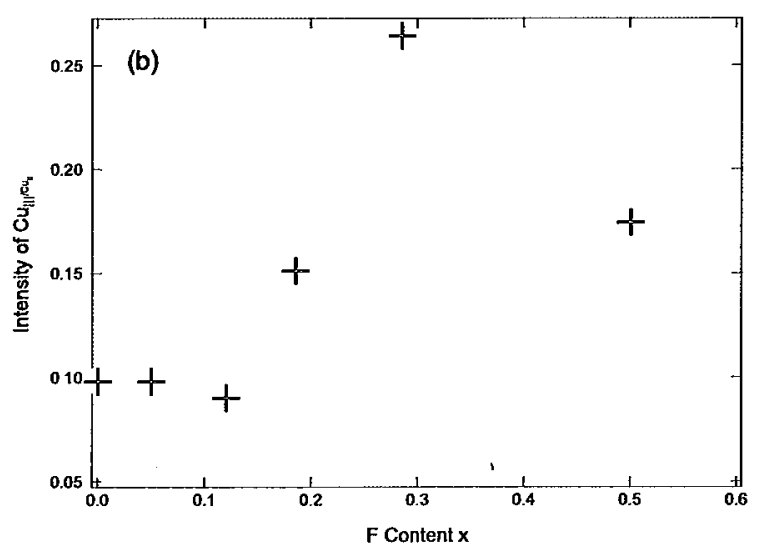

Figure 4. (a) $\mathrm{Cu} \mathrm{L} \mathrm{L}_{2,3}$-edge of $\mathrm{HgPb}-1223 / \mathrm{F}_{x}$ as a function of fluorine content $x$. (b) Intensity of the high energy shoulder $\left(\mathrm{Cu}^{3+}\right)$ relative to the main peak $\left(\mathrm{Cu}^{2+}\right)$. 
In other words, the hole concentration in the $\mathrm{CuO}_{2}$ planes of the under-doped $\mathrm{HgPb}-1223$ has been increased through fluorine addition. The behavior of this high energy shoulder resembles and confirms the behavior of the pre-edge peak in the $\mathrm{O}$ K-edge spectra that occurs at about $528.3 \mathrm{eV}$ and therefore supports the above assignment of the high energy shoulder in the $\mathrm{Cu} \mathrm{L}_{3}$-edge spectra to be coming from the $\mathrm{O} 2 \mathrm{p}$ hole states. It is known that the interstitial oxygen site $O(3)$ in the $\mathrm{Hg}-\mathrm{O}$ plane of $\mathrm{Hg}-1223$ is almost vacant [25-27]; therefore addition of fluorine will fill this empty oxygen vacancy and hence increases the number of holes in the $\mathrm{CuO}_{2}$ planes in the originally under-doped compound. Due to the high ionic and electronegative nature of $F^{-}$, it will show less hybridization with mercury and thus each fluorine ion will donate nearly one hole to the $\mathrm{CuO}_{2}$ planes $[21,22,25,26]$. This is unlike what happens in the case of fluorine addition to Tl-1223 with similar structure [1]. In Tl-1223 the corresponding oxygen site in the Tl-O plane is almost fully occupied but the site in the $\mathrm{CuO}_{2}$ plane is partially filled. Therefore in the case of T1-1223, fluorine will first fill these partially filled states in the $\mathrm{CuO}_{2}$ planes, and therefore reduces the hole concentration in the $\mathrm{CuO}_{2}$ planes of the originally over-doped Tl-1223 compound [1,21-24]. Further addition of fluorine beyond the optimum value will push the hole concentration in Hgpb1223 towards the over-doped side, and in the Tl-1223 towards the under-doped side of the bell-shaped phase diagram that is well established between the number of holes in the $\mathrm{CuO}_{2}$ planes and the superconducting properties $\left(T_{\mathrm{c}}\right)$ [3]. This is also in agreement with the behavior of the $\mathrm{Cu} \mathrm{L}_{3}$-edge and $\mathrm{O} \mathrm{K}$ edge pre-edge structure in figures 2 and 4 . These observations of the increase of the number of holes in $\mathrm{CuO}_{2}$ planes are consistent with our earlier observations of the improvements of the superconducting properties of the samples through fluorine addition [26, 27]. Furthermore, the improvements of the critical current density are also related to the number of holes in the $\mathrm{CuO}_{2}$ planes. It is also useful to mention at this point that the mechanism of hole doping through fluorine inclusion has also been affected as is clear from the improvements in both the field and temperature dependence of the magnetic hysteresis width published earlier at both low (intra-grain pinning) and high (inter-grain pinning) magnetic fields [26].

3.1.3. Ca $L_{2,3}$-edge. Figure 5 shows the $\mathrm{x}$-ray absorption spectra for the $\mathrm{Ca} \mathrm{L}_{2,3}$-edge of $\mathrm{Hg}-\mathrm{Pb}-1223 / \mathrm{F}_{x}$ for samples with different fluorine content $x$. The figure is plotted in order of increasing fluorine in the upwards direction, starting with $x=0$ for the lower curve. The structures in the spectra are mainly attributed to the $2 \mathrm{p}^{6} 3 \mathrm{~d}^{0}$ to $2 \mathrm{p}^{5} 3 \mathrm{~d}^{1}$ transition and did not show sensitivity to fluorine substitution, because there is no $\mathrm{Ca}-\mathrm{O}$ plane in the structure of the $\mathrm{Hg}-1223$ system. There are four clearly resolved features in the spectra at about peak $\mathrm{A}$ at $345 \mathrm{eV}$, peak $\mathrm{B}$ at $347.2 \mathrm{eV}$, peak $\mathrm{C}$ at $348.7 \mathrm{eV}$ and peak $\mathrm{D}$ at $350.5 \mathrm{eV}$, plus two shoulders at the low energy side of the main peaks (B and D), at 346.1 and $349.3 \mathrm{eV}$. The splitting between the two main peaks $\mathrm{B}$ and $\mathrm{D}$ is $3.3 \mathrm{eV}$, corresponding roughly to the spin-orbit splitting of $\mathrm{Ca} 2 \mathrm{p}$ cores. The splitting of each edge into two peaks $A$ and $B$ for $L_{3}$ and $C$ and $D$ for $L_{2}$ is evidence of the presence of a crystal field at Ca sites, and

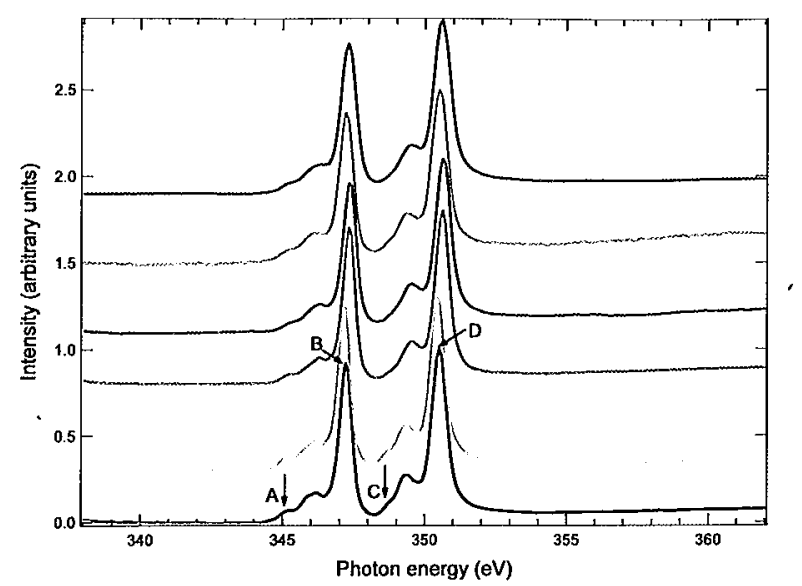

Figure 5. $\mathrm{Ca} \mathrm{L}_{2,3}$-edge for $\mathrm{Hg}-\mathrm{Pb}-1223 / \mathrm{F}_{x}$.

shows that $\mathrm{Ca}$ in $\mathrm{HgPb}-1223$, as in $\mathrm{Bi}-2223$ and in $\mathrm{Bi}-2212$, behaves in a nonmetallic manner, although the crystal field is more clear in the case of $\mathrm{Bi}-2212$ [41, 42].

The existence of crystal field splitting of Ca $3 d$ levels had been shown for various $\mathrm{Ca}$ compounds [42]. They have found a clear crystal field splitting for ionic compounds such as $\mathrm{CaO}$ and $\mathrm{CaF}_{2}$. They have also found that there is no crystal field splitting in the $\mathrm{Ca} \mathrm{L}_{2,3}$ spectra of $\mathrm{Ca}$ in a metallic environment such as $\mathrm{CaSi}_{2}$ [42]. The $\mathrm{Ca} \mathrm{L}_{2,3}$-edge structure and crystal field splitting in $\mathrm{HgPb} 1223 / \mathrm{F}_{x}$ is more similar to $\mathrm{CaF}_{2}$ and $\mathrm{CaO}$. $\mathrm{Ca}$ in $\mathrm{CaO}$ has a sixfold coordination, while $\mathrm{Ca}$ in $\mathrm{CaF}_{2}$ resides in a nearly cubic eightfold coordination as in the case in $\mathrm{Bi}$ 2212 [41]. The same argument is also true for $\mathrm{Hg}-\mathrm{Pb}-1223 / \mathrm{F}$. In both compounds $\mathrm{Ca}$ is located between two $\mathrm{CuO}_{2}$ planes. Therefore the peak splits off towards lower energy, i.e. peaks $A$ and $C$ can be assigned to the $e_{g}$ orbital while peaks B and D are assigned to the $\mathrm{t}_{2 \mathrm{~g}}$ orbital [41].

Figure 5 also shows two shoulders in the XANES Ca Ledge spectra of $\mathrm{HgPb}-1223 / \mathrm{F}_{x}$ samples at the lower energy side of the main peaks $B$ and $D$. These features have also been observed in $\mathrm{CaF}_{2}, \mathrm{Bi}-2212$ and $\mathrm{Bi}-2223$. Various authors attributed these features to $\mathrm{Sr} / \mathrm{Ca}$ mixing at the $\mathrm{Ca}$ site with the transition from a $2 p^{6} 3 d^{0} 4 s^{1}$ to $2 p^{5} 3 d^{1} 4 s^{1}$ states that corresponds to $\mathrm{Ca}^{+}$instead of $\mathrm{Ca}^{2+}$ ions. We also attribute these features for $\mathrm{HgPb}-1223 / \mathrm{F}_{x}$ to the same transition, as the structure of the $\mathrm{Ca}-\mathrm{O}$ sub-lattice is similar in each of $\mathrm{HgPb}-$ $1223 / \mathrm{F}_{x}$ and $\mathrm{Bi}-2212$ [41, 42]. The crystal field splitting observed for $\mathrm{HgPb}-1223 / \mathrm{F}_{x}$ compounds in other systems was not observed in Y-doped Tl-Pb-1212 compound [43].

\subsection{Cation substitution, $\left(\mathrm{Tl}_{0.5} \mathrm{~Pb}_{0.5}\right) \mathrm{Sr}_{2-x} \mathrm{Ce}_{x} \mathrm{Ca}_{2} \mathrm{Cu}_{3} \mathrm{O}_{10}$ system}

3.2.1. Oxygen K-edge. The resistivity measurement $[8,9]$ showed that there was an initial increase of the transition temperature $T_{\mathrm{c}}$ for the sample with $x=0.1$ followed by a decrease in the transition temperature. Superconductivity vanished for the sample with $x>0.3$, indicating a severe change in the hole concentration in the $\mathrm{CuO}_{2}$ planes as $\mathrm{Ce}$ 

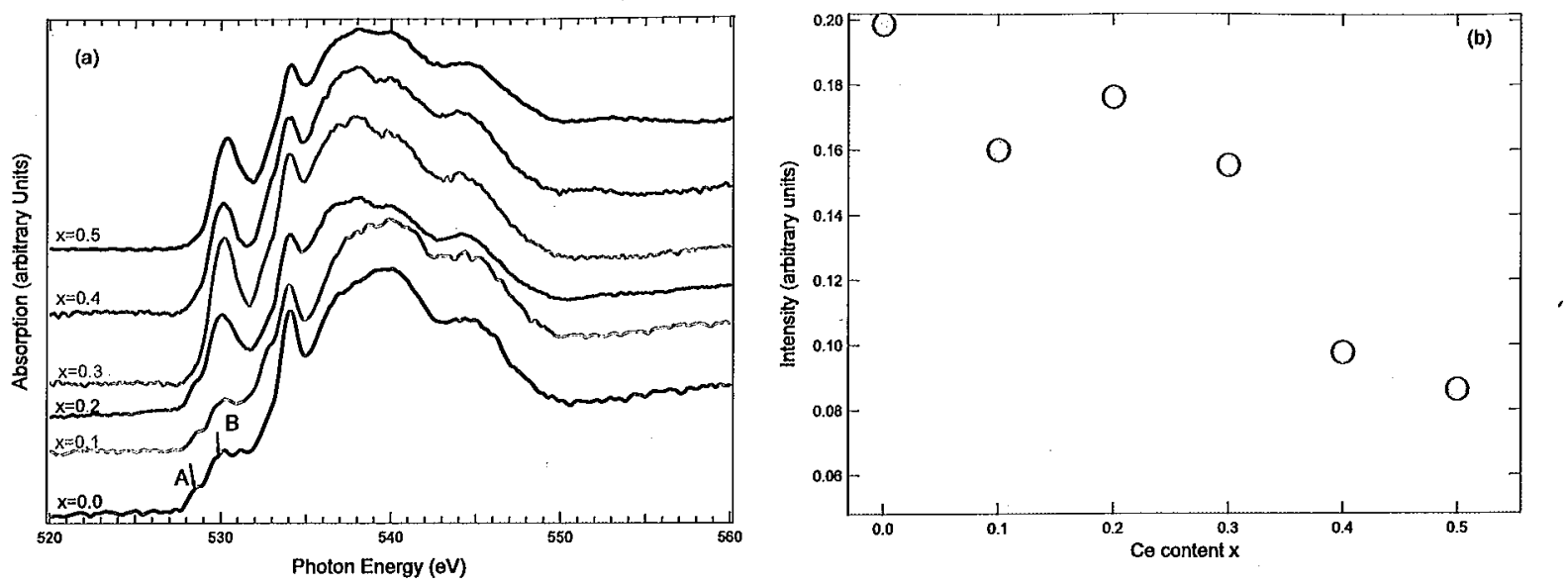

Figure 6. (a) $\mathrm{O}$ K-edge XANES spectra for $\left(\mathrm{Tl}_{0.5}, \mathrm{~Pb}_{0.5}\right) \mathrm{Sr}_{2-x} \mathrm{Ce}_{x} \mathrm{Ca}_{2} \mathrm{Cu}_{3} \mathrm{O}_{y}$ system for different values of $x$. (b) Intensity of the pre-edge feature (A) with Ce content $x$.

with a valence state higher than $2+$ replaces $\mathrm{Sr}^{2+}$ in the $\mathrm{SrO}$ planes [9]. Magnetic measurements showed a decrease in the magnetic hysteresis width as Ce content was increased, indicating that $\mathrm{Ce}$ incorporation at the $\mathrm{Sr}$ site does not enhance the phase formation of the superconducting phases $[8,9]$. The superconducting fraction of the samples was decreased drastically for Ce content $x>0.1$.

Figure 6(a) shows the normalized $\mathrm{O}$ K-edge $\mathrm{x}$-ray absorption spectra for $\left(\mathrm{Tl}_{0.5} \mathrm{~Pb}_{0.5}\right) \mathrm{Sr}_{2-x} \mathrm{Ce}_{x} \mathrm{Ca}_{2} \mathrm{Cu}_{3} \mathrm{O}_{10}$ of different $\mathrm{Ce}$ content $x$. The spectra shown in this work were collected using the drain current mode.

The spectra had been normalized to the incident photon intensity $\left(I_{0}\right)$ measured simultaneously by an Au mesh located upstream after the exit slit and the refocusing mirror. All spectra were then normalized so that they have the same absorption at the energy $560 \mathrm{eV}$, where there is no feature associated with the oxygen K-edge of these compounds.

These spectra are indications of the projected local density of unoccupied states on the $\mathrm{O}$ sites. Therefore, the region very close to the absorption edge is a measure of $O 2 p$ hole concentration in the valence band. The spectra are the superposition of unoccupied states that arise from $\mathrm{Cu}-\mathrm{O}, \mathrm{Ca}$, $\mathrm{Sr}(\mathrm{Ce})-\mathrm{O}$ and $\mathrm{Tl}(\mathrm{Pb})-\mathrm{O}$ layers. The pre-edge structure is attributed to transitions from $O 1$ s core states to holes with $2 \mathrm{p}$ symmetry on the oxygen sites. The first pre-edge starts at about $527.4 \mathrm{eV}$, which corresponds to the Fermi level.

The first feature in the pre-edge structure is a peak at about $528.6 \mathrm{eV}$ and could be assigned to arise from $\mathrm{Cu}-\mathrm{O}$ layers. It can be ascribed to the transition from $3 \mathrm{~d}^{9} \mathrm{~L} \rightarrow \mathrm{O} 1 \mathrm{~s} 3 \mathrm{~d}^{9}$ ( $\mathrm{L}$ denotes a hole on the $\mathrm{O} 2 \mathrm{p}_{x, y}$ orbital) states corresponding to creation of a core hole on the $\mathrm{O} 1 \mathrm{~s}$ level and filling of $\mathrm{O} 2 \mathrm{p}_{x, y}$ states admixed to the upper Hubbard band. This transition is strongly related to the hole concentration in $\mathrm{CuO}_{2}$ and is identical to the corresponding peak discussed above for $\mathrm{HgPb}$ $1223 / \mathrm{F}_{x}[34-40]$.

Our samples consist of a mixture of Tl-1223 and Tl-1212 phases. It is well established that as-prepared Tl-1223 samples are always mixed with the Tl-1212 phase. In particular, it was found to be impossible to obtain a Ce-doped Tl-1212 or Tl-1223 phase $[1,8,9,44,45]$. At the same time, both Tl-1223 and Tl-1212 superconducting phases are overdoped and have similar layered structures, especially from the hole concentration and $\mathrm{Cu}$ valence point of view. Therefore, our $\mathrm{x}$-ray absorption results will not distinguish the $\mathrm{O} \mathrm{K}$ edge, $\mathrm{Cu}$ L-edge and Ce M-edge XANES spectra for the two phases. The valence state of $\mathrm{Cu}$ for both phases is the same $(2.2+)[1,5,45]$.

In figure $6(\mathrm{~b})$, we present the variation of the intensity of the pre-edge peak at about $528.6 \mathrm{eV}$ with Ce content $x$. The figure shows a decrease of the peak's intensity as the Ce content $x$ is increased which is a direct measure of hole concentration in $\mathrm{CuO}_{2}$ planes and a confirmation of our earlier expectations that the hole concentration in $\mathrm{CuO}_{2}$ planes decreases as $\mathrm{Ce}$ (in the valence state $\mathrm{Ce}^{3+}$ and $\mathrm{Ce}^{4+}$ ) replaces $\mathrm{Sr}^{2+}$ in the metallic layer $\mathrm{Sr}-\mathrm{O}$. As $\mathrm{Ce}$ exists in a mixed valence state of +3 and +4 , as we will see later in this paper, and because the unsubstituted sample is in the over-doped (over-oxidized) state, the valence state of $\mathrm{Cu}$ will be reduced, and therefore $T_{\mathrm{c}}$ will initially increase to a maximum value as the density of holes goes through its maximum and then decrease as we cross to the under-doped state. This result is in agreement with our measurement of the variation of the transition temperature of these samples with Ce content $x[8,9]$. The increment of the Ce content $x$ in this study seems to be very large. To scan the variation of the hole concentration with the $T_{\mathrm{c}}$, we are working on substituting $\mathrm{La}$ in much smaller increments in the $\mathrm{Sr}$ site, rather than $\mathrm{Ce}$. Initial measurements indicate that $T_{\mathrm{c}}$ gradually increases to reach a maximum value as the La content was increased. XANES measurements for the La-substituted Tl1223 are being planned.

The assignment of the first pre-edge peak at $528.6 \mathrm{eV}$ for the $O(1)$ and $O(1)^{\prime}$ agrees with local density-of-states calculations (LDA) of Tl-2223 by Marksteiner et al and also agrees with several authors for various $\mathrm{Tl}$-based, $\mathrm{Hg}$ based and Bi-based superconductors as these systems have similar structures $[31,32,36]$. Following the same reasoning 
and utilizing the results of the LAD calculations [36], we can ascribe the second pre-edge feature at $529.4 \mathrm{eV}$ with the $\mathrm{O} 2 \mathrm{p}$ holes in $\mathrm{O}(2)$ site of the $\mathrm{Sr}-\mathrm{O}$ planes. These holes are with predominantly $\mathrm{O} 2 \mathrm{p}_{z}$ symmetry, as proven by polarization effects. The intensity of this peak increased on going from $E 1 \mid a b$ to $E 1 \mid c$ polarization, i.e. this peak has $O$ $2 \mathrm{P}_{z}$ symmetry $[31,34]$.

The third pre-edge peak at about $530 \mathrm{eV}$ is ascribed to the $\mathrm{O} 2 \mathrm{p}$ holes in the $\mathrm{O}(3)$ atoms within the Tl-O plane. This is consistent with the above discussions and results obtained for various $\mathrm{Tl}$-based and $\mathrm{Hg}$-based phases in both single crystals and polycrystalline samples $[31,46]$.

3.2.2. $\mathrm{Ce} \mathrm{M}_{4,5}$-edge. X-ray absorption spectra (XAS) spectra at the $\mathrm{Ce} \mathrm{M}_{4,5}$-edge is shown in figure 7 . The spectra exhibit two main peaks known to be due to $3 \mathrm{~d}_{3 / 2}\left(\mathrm{M}_{4}\right)$ and $3 \mathrm{~d}_{5 / 2}$ $\left(\mathrm{M}_{5}\right)$ multiplet structures of the $3 \mathrm{~d}^{9} 4 \mathrm{f}^{2}$ final state $\left(\mathrm{M}_{5}\right.$ main peak at $883.1 \mathrm{eV}$ and $\mathrm{M}_{4}$ main peak at $901.1 \mathrm{eV}$ ). The Ce Medge spectra are well separated $(\sim 18 \mathrm{eV})$ due to large spinorbit splitting between $M_{4}$ and $M_{5}$. Features at the higher energy side of the main peaks separated by $(\sim 5 \mathrm{eV})$ from the main peaks are driven by Coulomb interactions between the $3 \mathrm{~d}$ core hole and the $4 \mathrm{f}$ sub shell, and by the Coulomb repulsion between $4 \mathrm{f}$ electrons. These two features are believed to arise from the transition from the initial ground state to the $3 \mathrm{~d}^{9} 4 \mathrm{f}^{\mathrm{l}}$ final state [47]. These secondary peaks in $\left(\mathrm{Tl}_{0.5}\right.$, $\left.\mathrm{Pb}_{0.5}\right) \mathrm{Sr}_{2-x} \mathrm{Ce}_{x} \mathrm{Ca}_{2} \mathrm{Cu}_{3} \mathrm{O}_{y}$ are very similar to those observed in $\mathrm{CeCO}_{2}, \mathrm{CeRh}_{2}$ and $\mathrm{CeRh}_{3}$ and are indicative of a mixed valence state of $\mathrm{Ce}$ in these solid solutions. Therefore, we believe that the $\mathrm{Ce}$ state is a mixture of $\mathrm{Ce}^{4+}$ and $\mathrm{Ce}^{3+}$ in these samples This result was also observed in Ce-doped$\mathrm{Bi}-1223.223$ [48]. The ground state of $\mathrm{Ce}$ in the Tl-1223Ce compound can be described as a mixture of the $4 \mathrm{f}^{\circ}$ and $4 \mathrm{f}^{1}$ states, such that the Ce $\mathrm{M}_{4,5}$-edge in the XANES spectra exhibits a peak corresponding to the transition $i \rightarrow 3 \mathrm{~d}^{9} 4 \mathrm{f}^{1}$ at $888 \mathrm{eV}$ and $906.1 \mathrm{eV}$, respectively, and $i \rightarrow 3 \mathrm{~d}^{9} 4 \mathrm{f}^{2}$ at about 883 and $906.1 \mathrm{eV}$, where $i$ is the initial ground state. The intensity ratio of the high energy shoulder $\left(i \rightarrow 3 \mathrm{~d}^{9} 4 \mathrm{f}^{1}\right)$ transition to that of the main peak $\left(i \rightarrow 3 d^{9} 4 f^{2}\right)$ does not change as the Ce content $x$ was increased in the samples (about 0.6 ), indicating that the average Ce valence does not change, from sample to sample.

In summary, the $\mathrm{Ce}_{4,5}$ XAS spectra show that Ce exists in a mixed valence state of $3+$ and $4+$. This result is a confirmation of previous expectations for the valence state of $\mathrm{Ce}$ in Tl-1212 [49, 50]. As this state is larger than that of $\mathrm{Sr}$ $(2+)$, this will lead to hole filling, and hence a decrease in the valence state of $\mathrm{Cu}$ in the $\mathrm{Cu}-\mathrm{O}_{2}$ planes.

\section{Conclusions}

In this study, we have found that the hole concentration in the $\mathrm{Cu}-\mathrm{O}_{2}$ planes of $\mathrm{Pb}$-doped $\mathrm{Hg}-1223\left(\mathrm{HgPb}-1223 / \mathrm{F}_{x}\right)$ increases with fluorine addition. As we have indicated in earlier studies fluorine should be replacing the interstitial oxygen site in the $\mathrm{Hg}-\mathrm{O}$ plane, which has low occupancy in order to contribute to the increase of the hole concentration in the $\mathrm{CuO}_{2}$ planes. The variation of the peak intensity of the pre-edge feature of

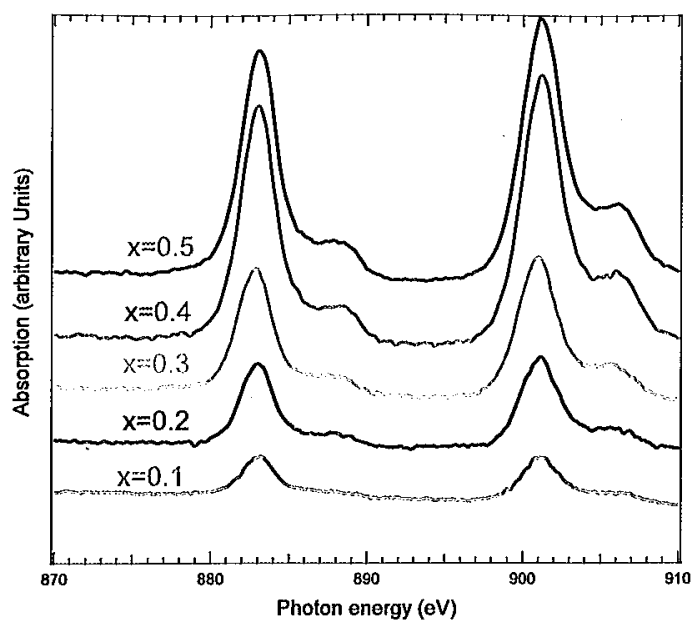

Figure 7. $\mathrm{Ce} \mathrm{M}_{4,5}$-edge for $\left(\mathrm{Tl}_{0.5}, \mathrm{~Pb}_{0.5}\right) \mathrm{Sr}_{2-x} \mathrm{Ce}_{x} \mathrm{Ca}_{2} \mathrm{Cu}_{3} \mathrm{O}_{y}$ system for different values of $x$.

the $\mathrm{O} \mathrm{K}$-edge associated with the number of $\mathrm{O} 2 \mathrm{p}$ holes in the $\mathrm{CuO}_{2}$ layers and the intensity of the high energy shoulder in the $\mathrm{Cu} \mathrm{L}_{3}$ absorption edge increase gradually before they start decreasing for higher fluorine content. The presence of a crystal field as evident from the multiple structures of the $\mathrm{Ca} \mathrm{L}_{2}$ and $\mathrm{L}_{3}$ edges shows that $\mathrm{Ca}$ behaves as nonmetallic in this system. The above results are in agreement with our observed improvements in the superconducting properties of these systems [1, 26, 27].

Furthermore, we have found that $\mathrm{Ce}$ substitution in the over-doped Tl-1223 system $\left(\left(\mathrm{Tl}_{0.5}, \mathrm{~Pb}_{0.5}\right) \mathrm{Sr}_{2-x} \mathrm{Ce}_{x} \mathrm{Ca}_{2} \mathrm{Cu}_{3} \mathrm{O}_{y}\right)$ decreases the number of holes in the $\mathrm{Cu}-\mathrm{O}_{2}$ planes gradually to the under-doped regime. This was clear from the behavior of the intensity of the pre-edge peak in the $\mathrm{O} \mathrm{K}$-edge structure for samples with different $\mathrm{Ce}$ contents. The $\mathrm{Ce}_{4,5} \mathrm{XAS}$ structure showed that Ce exists in a higher valence state $(3+$ and $4+)$ compared to $\mathrm{Sr}(2+)$, leading to the observed reduction in the number of holes in the $\mathrm{Cu}-\mathrm{O}_{2}$ planes and hence affecting the superconducting properties such as the transition temperature.

\section{Acknowledgments}

The Hg-based samples used in this work were prepared during the sabbatical leave of NMH at the National High Magnetic Field Laboratory in collaboration with Professor Justin Schwartz and Dr Sastry Pamidi. This work was partially funded from the DOE-BES. NMH would like to acknowledge the support of the Abdus Salam ICTP in Trieste, Italy. Special thanks are due to Dr M Faiz, and Dr S B Mun for their help in the data collection and discussions.

\section{References}

[1] Hamdan N M, Ziq Kh A and Al-Harthi A S 1999 Physica C 314125

[2] Karppinen M, Kotiranta M, Yamauchi H, Nachimuthu P, Liu R S and Chen J M 2001 Phys. Rev. B 63184507 
[3] Paranthaman M P, Manthiram A and Goodenough J B 1994 Thallium-Based High Temperature Superconductors ed A M Herman and Y J Yakhmi (New York: Dekker) p 171

[4] Pan M H and Greenblatt M 1991 Physica C 17680

[5] Liu R S and Edwards P P 1994 Thallium-Based High Temperature Superconductors ed A M Herman and J Y Yakhmi (New York: Dekker) pp 325-46

[6] Hamdan N M, El-Ghanem H and Schwartz J 2000 IEEE Trans Appl. Supercond. 101174

[7] Hamdan N M, Ziq Kh A, Al-Harthi A S and Shirokoff J 1998 J. Supercond. 1195

[8] Hamdan N M 1999 J. Low Temp. Phys. 1171187

[9] Hamdan N M 2000 IEEE Trans. Appl. Supercond. 101170

[10] Hamdan N 2000 Physica B 284-288 1093-4

[11] Putlin S N, Antipov E V, Chmaissem O and Marezio M 1993 Nature 362226

[12] Sekhar B R, Studer F, Garg K B, Moriwaki Y, Gasser C and Tanabe K 2001 Phys. Rev. B 56134506

[13] Marezio M, Capponi J J, Radaelli P G, Edwards P P, Armstrong A R and David W I F 1994 Eur. J. Solid State Inorg. Chem. 31 843-54

[14] Alonso R E, Rodrigues C O and Christensen N E 2001 Phys. Rev. B 63134506

[15] Singh D J and Pikett W E 1994 Phys. Rev. Lett. 73476

[16] Novokov D L and Freeman A J 1993 Physica C 216273

[17] Serquis A, Caneiro A, Basset A, Short S, Hodges L P and Jorgensen J 2001 Phys. Rev. B 6314508

[18] Sastry P V P S S, Amm K M, Knoll D C, Peterson S C and Schwartz J 1998 Physica C 297223

[19] Sastry P V P S S and Schwartz J [998 J. Supercond. 11592

[20] Fabrega L, Fontcuberta J, Serquis A and Caneiro A 2001 Physica C $356254-60$

[21] Hamdan N M, Ziq Kh A and Al-Harthi A S 1996 J. Low Temp. Phys. 1051493

[22] Faiz M and Hamdan N M 2000 J. Electron Spectrosc. Relat. Phenom. 107283

[23] Hamdan N M and Faiz M $2001 \mathrm{~J}$. Electron Spectrosc. Relat. Phenom. 114-116 291-4

[24] Hamdan N M, Al-Harthi A S and Choudhary M F 1997 Physica C 282-287 2273-4

[25] Peacock G B, Gameson I, Slaski M, Capponi J J and Edwards P P 1997 Physica C 289153

[26] Hamdan N M, Sastry P V P S S and Schwartz J 2002 IEEE Trans. Appl. Supercond. $121132-5$

[27] Hamdan M, Sastry P V P S S and Schwartz J 2000 Physica C 341-348 513
[28] Putilin S N, Antipov E V, Abakumov A M, Rozova M G, Lokshin K A, Pavlov D A, Balagurov A M, Sheptyakov D V and Marezio M 2000 Physica C 33852

[29] Lockshin K A, Pavlov D A, Putilin S N, Antipov E V, Sheptyakov D V and Balagurov A M 2001 Phys. Rev. B 6364511

[30] Wang Y T and Hermann A M 1995 Physica C 2541

[31] Chen J M, Liu R G, Liu R S, Lin H C, Uen T M, Juang J Y and Gou Y S 1997 Chem. Phys. Lett. 276303

[32] Pellegrin E, Fink J, Chen C T, Xiong Q, Lin Q M and Chu C W 1996 Phys. Rev. B 532767

[33] Kawa J et al 2000 Spectrochim. Acta B 55 1385-95

[34] Liu R S, Chen J M and Shy D S 1997 Inorg. Chem. 361378

[35] Saini N L, Law D S-L, Pudney P, Srivastava P, Menovsky A, Franse J J M, Ohkubo H, Akinaga H, Studer F and Garg K B 1995 Physica C 2517

[36] Marksteiner P, Yu J, Massidda S and Freeman A J 1998 Phys. Rev. B 392894

[37] Chen J M, Liu R S and Hu S F 1996 Physica C 272180 Chen J M, Chung S C and Liu R S 1996 Solid State Commun. 99493

[38] Chen J M, Liu R S and Linag W Y 1996 Phys. Rev. B 5412587

[39] Karppinen M, Kotiranta M, Nakane T, Yamauchi H, Chang S C, Liu R S and Chen J M 2003 Phys. Rev. B 67134522

[40] Karppinen M, Yamauchi H, Nakane T, Fujinami K, Lehmus K, Nachimuthu P, Liu R S and Chen J M 2002 J. Solid State Chem. 166229

[41] Qvarford M, Andersen J N, Nyholm R, van Acker J F, Lundgren E and Lindan I 1992 Phys. Rev. B 4614126

[42] Himpsel F J, Karlsson U O, McLean A B, Terminello L J, de Groot F M F, Abbate M, Fuggle J C, Yarmoff J A, Thole B T and Sawatzky G A 1991 Phys. Rev. B 436899

[43] Liu R S and Chen J M 1998 Supercond. Sci. Technol. 11 1028-31

[44] Hong Q and Wang J H 1993 Physica C 217 $439-43$

[45] Nakajima S, Kikuchi M, Syono Y, Oku T, Nagase K, Kobayashi N, Shindo D and Hiraga K 1991 Physica C $18289-94$

[46] Krol A et al 1990 Phys. Rev. B 42 2635-8

[47] Vavassori P, Duo L, Chiaia G, Qvarford M and Lindau I 1995 Phys. Rev. B 436899

[48] Liang G, Yao Q, Zhou S and Katz D 2005 Physica C $424107-115$

[49] Hong Q and Wang J H 1993 Physica C 217 $439-43$

[50] Lee W H and Wang D C 1995 Physica C 253 156-64 


\section{DISCLAIMER}

This document was prepared as an account of work sponsored by the United States Government. While this document is belieyed to contain correct information, neither the United States Government nor any agency thereof, nor the Regents of the University of California, nor any of their employees, makes any warranty, express or implied, or assumes any legal responsibility for the accuracy, completeness, or usefulness of any information, apparatus, product, or process disclosed, or represents that its use would not infringe privately owned rights. Reference herein to any specific commercial product, process, or service by its trade name, trademark, manufacturer, or otherwise, does not necessarily constitute or imply its endorsement, recommendation, or favoring by the United States Government or any agency thereof, or the Regents of the University of California. The views and opinions of authors expressed herein do not necessarily state or reflect those of the United States Government or any agency thereof or the Regents of the University of California.

This work was supported by the U.S. Department of Energy under Contract No. DE-AC02-05CH11231 